\title{
Arbor
}

\section{Reflexiones sobre la Didáctica de la enseñanza/aprendizaje de la Lengua y la Literatura}

Joaquín Díaz-Corralejo

Arbor CLXXIII, 681 (Septiembre 2002), 129-152 pp.

La creación de sentido sirviéndose del lenguaje es una necesidad instrumental vital para dotar(se) de significado a sí mismo, al otro y al mundo. La Didáctica de las lenguas, de las literaturas y de las culturas debe ser el eje sobre el que se construya el sentido en el resto de las disciplinas. Las lenguas maternas y extranjeras son los elementos instrumentales necesarios en sociedades multiculturales con una inmigración importante. A partir de estas premisas, se verá la progresión de secuencias didácticas en Lengua y Literatura. Así mismo, partiendo de la importancia y del papel de la Lengua y de la Literatura en el sistema educativo, se propondrá un nuevo paradigma.

"Todavía queda una revolución que coloque en primer plano el estudio del significado y de la situación»

Ignasi Vila ${ }^{1}$

\section{El acceso al sentido}

La creación de sentido sirviéndose del lenguaje es una necesidad instrumental vital para dotar(se) de significado a sí mismo, al otro y al mundo. Toda cultura trata de equipar a sus futuros ciudadanos con modelos 
y procedimientos que perfeccionen esas habilidades, sin ellas no se podría desarrollar una cultura (Bruner 1990, p. 99). La evocación mental con toda su complejidad es interpretada de forma incompleta y pálida por el lenguaje: «Pensar en castellano, inglés o catalán es una riqueza y un lío...; si me preguntan en qué idioma pienso, digo que lo hago en imágenes» (Graves 1999, p. 14).

El sistema escolar proporciona al niño, al adolescente, en primer lugar, un entorno humano representativo de la comunidad en la que se hará persona; en segundo lugar, la lengua materna y/o la lengua oficial, las distintas asignaturas que utilizan también dichas lenguas y las lenguas extranjeras conforman los procesos que van formando los criterios del juicio crítico que le permitirá analizar y valorar interpretando la realidad (Lipman 1991, p. 36).

Las lenguas llenarán de sentido para los estudiantes la relación entre las actividades, los ejercicios y las tareas que se les proponen para desarrollar las habilidades, los conocimientos y las conductas y su biografía personal. Pues para Bruner (1990, p. 75) es en la interacción donde se construye el sentido: «los seres humanos, al interactuar entre sí, crean un sentido de lo canónico y lo ordinario que se constituye en telón de fondo sobre el que poder interpretar y narrar el significado de lo inusual».

Pero para interactuar en las mejores condiciones hace falta (Galisson 1991, p. 161): «A) Utilizar modelos de comportamiento (porque los comportamientos, actualizados en situación de uso, obedecen a reglas interiorizadas, organizadas según modelos, lo mismo que los discursos constituyentes de un enunciado ${ }^{2}$ ). B) Movilizar las representaciones del mundo» ${ }^{3}$.

Es decir, para Galisson, los saber-hacer de interacción, la práctica cotidiana, necesitan de saberes multiculturales, representaciones del mundo, para comprender y expresar el sentido.

En el aprendizaje de las lenguas, de las literaturas y de las culturas ambos aspectos tienen que ser tomados en cuenta en la planificación del currículo en las secuencias de aula. Hay que proporcionar elementos de reflexión y habilidades para analizar modelos y representaciones. Sin ellos, todo aprendiz carecerá de criterios para aceptar o rehusar la información que recibe o que envía. Algo cada vez más necesario pues los medios de comunicación transmiten hechos culturales de todo tipo con una intencionalidad siempre implícita, alienante y escasamente formativa.

Ese diseño debe considerar la construcción del sentido en los tres ejes de la significación (Morris 1971 y Jacques 1987): 
1. Eje de la referencia (de qué se habla, léxico-semántico y socio-cultural).

2. Eje de la diferencia o de los materiales significantes (cómo se dice y con qué, lingüístico-fonético-fonológico).

3. Eje de la comunicabilidad (quién habla a quién y por qué, pragmático).

Estos tres ejes también han sido estudiados por la psicolingüística, que propone también tres fases para la comprensión o la expresión del sentido. Hay que poner en relación la situación de comunicación y el sistema lengua con la realidad del enfoque perceptivo de los alumnos. Esta relación, en una primera hipótesis, podría tener un planteamiento en tres etapas que parecen ser las que los alumnos siguen en la práctica (García 1994):

a) Búsqueda del sentido global: reconocimiento grafémico, fonológico y ortográfico en relación con el léxico.

b) A esta primera hipótesis se añade el reconocimiento sintáctico y pragmático (actos de habla en relación con la situación de enunciación).

c) Integración texto/discurso.

No hay un orden obligatorio en este enfoque perceptivo, aparentemente las tres etapas se activan a la vez en interacción constante.

La implicación de todo esto en la transposición a los saber-hacer del profesor para su aplicación al aula sería esta:

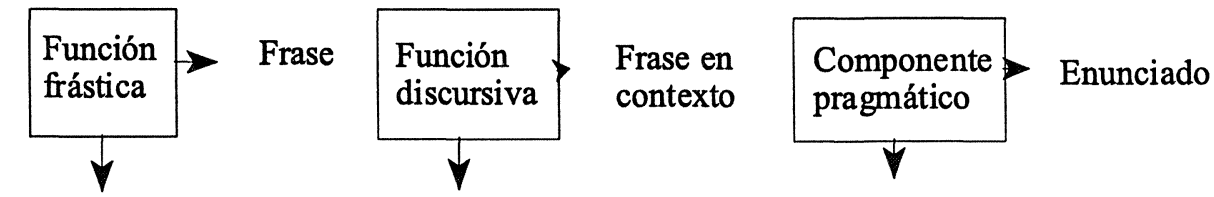

El sentido como lugar de las condiciones verídicas

Aceptabilidad
Inserción en el discurso

Cohesión textual en el contexto temático
Interpretación en la situación enunciativa o de comunicación

Coherencia textual en el contexto social, no verbal, etc.

(Cuadro adaptado de Robert Martin (1983, 2a ed.1992): Pour une logique du sens París: P.U.F., p. 17).

Que parte de las funciones para llegar a la enunciación en situación, integrando los cuadros anteriores. 


\section{Multiculturalidad, emigración y aprendizaje de las lenguas, las literaturas y las culturas}

«El objetivo de la cultura debe ser mantener al otro vivo y celebrar su complejidad»

Hanif Kureishi

La realidad española demuestra, con su gran diversidad de lenguas, que hay una gran riqueza no sólo en los aspectos literarios y artísticos, sino en la generosidad, el talante abierto y comprensivo, estereotipo de los españoles, que es fruto de la convergencia y sincretismo de lenguas y culturas.

Como todo currículo es un producto implícito de ciudadano, el aprendizaje de las lenguas debe servir, además de (re)centrar el ego del estudiante al entrar en contacto con otras culturas, para que dicho proyecto de persona se haga explícito. Esa puede ser la respuesta a la violencia egocéntrica, a la cerrazón comunitaria, al eurocentrismo y a la globalización. La sociedad está pidiendo al sistema educativo soluciones a hechos sociales que implican una sensibilización social: el paro, el hambre, la enfermedad, la contaminación, la guerra y el terrorismo, por no citar más que las más actuales y terribles. Ante la pérdida de poder de decișión a niveles globales, parece que habrá que formar unas generaciones que lo recuperen a nivel de barrio, de ciudad.

La Didáctica de las lenguas y de las literaturas debe ser el eje sobre el que se construya el resto de materias. La lengua materna y las lenguas extranjeras son los elementos instrumentales necesarios en sociedades multiculturales con una inmigración importante.

Dichas lenguas servirán de elemento sincretizador a lo largo del currículo, pero si se quiere evitar lo que Berstein llama «barrera lingüística» (que implica que los estudiantes de clases desfavorecidas y de minorías marginadas fracasen en lenguas), hay que combatir las «estrategias restringidas» en la planificación verbal, tanto en la socialización primaria (grupo social) en la familia y en la escuela, como en la secundaria (trabajo) por medio de la diversificación de las interacciones sociales y del conocimiento de las habilidades metalingüísticas para observar el funcionamiento de las lenguas a fin de poder interiorizarlas.

Por ejemplo, en Primaria y en la ESO se pueden emplear textos de referencia cultural: mitos, fábulas, cuentos, poemas, de diferentes culturas, más adelante, grandes textos literarios ${ }^{4}$, así como la literatura infantil y juvenil, y textos documentales, al tiempo que se inicia el estudio de las metaestrategias elementales de análisis, reflexión y organización mental. 
Para los hijos de los inmigrantes habrá que proporcionar textos orales y escritos en sus lenguas maternas. Los profesores deberán recibir información y formación en otras culturas y en otras formas de aprendizaje cultural. Cuando haya grandes grupos de alumnos con una misma lengua materna u oficial, además de otros planes en marcha, se ha comprobado ${ }^{5}$ que es más rentable, tanto a nivel educativo como económico, mantenerlos, durante los tres primeros años de incorporación al sistema, en contacto con esas lenguas ${ }^{6}$ en las asignaturas fundamentales, lengua, matemáticas, y quizá ciencias sociales, dibujo, al tiempo que estudian español, esto les permite seguir avanzando a su ritmo cognitivo e incorporarse de forma más sencilla para una integración total al cuarto año. De no hacerse así, sufren un retraso general que es más difícil de recuperar después.

Se trataría de fomentar un cierto bilingüismo en un entorno multicultural (Vez 1988).

\section{Paradigma educativo y currículo: hacia un nuevo paradigma}

La sociedad se encuentra en un momento en el que están coexistiendo dos visiones contradictorias del caos de la realidad.

La visión mecanicista (cartesiana, lineal, optimismo irrealista).

La mente es superior al cuerpo. El observador está separado y es neutral ante lo observado.

- Necesidad de dividir el conocimiento en disciplinas.

El conjunto es la suma de las partes. Relación de causa-efecto: pensamiento analítico, lineal y monocausal.

Vida humana superior a la naturaleza. Desarrollo ilimitado.
La visión holista (sistemática, ecológica, pesimismo realista).

La mente y el cuerpo en un todo integrado. El observador interactúa con lo observado. Interrelación disciplinar.

El todo es más que la suma de las partes. Red causal: pensamiento complejo, borroso, y helicoidal.

Vida humana integrada en un uniterso complejo y caótico.

Desarrollo sostenible.

En esta situación mundial se está (re)creando como nuevo el paradigma de los derechos humanos: la solidaridad mundial. 
El sistema educativo también vive en contradicción:

La visión mecanicista

Los contenidos científicos son superiores a la metodología.

La organización es burocrática, cartesiana y disciplinar.

La enseñanza es memorística, superficial y fragmentaria.

La evaluación aparece como control y clasificación.
La visión holista

Los contenidos y la metodología son dos caras de la misma moneda.

La organización es compleja, interdisciplinar y transversal.

La enseñanza/aprendizaje es conceptualizadora y global.

La evaluación aparece como formación e intervención.

Quizá la solución esté en un nuevo paradigma educativo: ción.

Disciplinas: esquemas lógicos para mejor comprensión de la informa-

Metodología humanista y transversal: análisis de la información en situación dentro de una cultura.

Cultura: sistema de juicio y de pensamiento creativo

Enfoques holistas y ecológicos

Ética de mínimos

Áreas de transversalidad

Estrategias transversales

\section{Didáctica de las lenguas, de las literaturas y de las culturas}

En el aprendizaje de las lenguas, las literaturas y de las culturas, el soporte básico es el texto en todas sus categorías. Dicho aprendizaje tiene como objetivo primordial el dominio funcional del lenguaje y como objetivos fundamentales (Bronckart 1997, p. 34): 1. La formación de la persona. 2. La formación comunicativa. 3. La construcción de las funciones sociales. 4. El análisis y la reflexión. 5. La formación a la diversidad social

La didáctica de la lengua y del texto deben ser solidarias y complementarias. Tanto el campo de la enseñanza/aprendizaje de las lenguas, como el literario se desarrollan epistemológicamente en la contradicción y la dialéctica de todo campo científico. Se trata de formar a la vez lo individual y lo social, la comprensión del texto en su función específica y de su relación diversa con los demás textos, el conocimiento social y cultural del entorno textual y literario y su relación con el resto de la humanidad, en fin, el dominio del sistema como paradigma y de la diversidad de relaciones y de producción textual. 
Todo esto implica que el paradigma de didáctica de las lenguas, de las literaturas y de las culturas debe ser el proceso de enseñanza/aprendizaje de acceso y construcción del sentido a través de las lenguas, las literaturas y las culturas. Y su finalidad mejorar las condiciones educativas de la transmisión, de la transposición y de la adquisición de lenguas, literaturas y culturas maternas, segundas y/o extranjeras.

Dentro de ese paradigma, el docente necesita hacer un análisis de la situación de enseñanza/aprendizaje que le proporcione los datos de los alumnos y del centro en relación con el currículo del curso y del grupo clase concernido.

\section{Análisis situación de enseñanza / aprendizaje global}

Datos socio-antropológicos:

Internos: La «situación», «distancia» (Dabène, 1990) entre LM, LO y $\mathrm{LE}^{7}$ que posibilita/dificulta la introducción de la LM/LE como lengua «vehicular».

El nivel sociolingüístico alcanzado en la lengua vernácula, o, en su caso, la lengua materna, es decir, si se elaboran en ella las funciones simbólica y conceptual.

Externos: La extracción social de los alumnos.

La pertenencia cultural y étnica de los alumnos.

Las perspectivas de movilidad social de la zona.

Las expectativas de la Asociación de Padres de Alumnos.

Las expectativas de los alumnos.

Las actividades culturales (Ayuntamiento, Comunidad, etc.).

Las actividades culturales dominantes entre los alumnos.

Las perspectivas de desarrollo tecnológico.

Etc.

Datos psicocognitivos:

Perfiles psicológicos: introvertido - extravertido - apático

$$
\text { motivado - tímido - hiperactivo }
$$

Perfiles físicos y cognitivos: visual/auditivo - serialista/globalista dependiente/independiente perfeccionista/realista

Actitudes: comportamientos negativos/positivos

Conductas: interrelaciones personales y de grupo

Datos epistemológicos:

Metodología general del centro 
Metodología del seminario y del área

Propuestas interdisciplinares y multiculturales

Propuestas profesores

Datos didácticos:

Marco curricular, social, político y económico

Objetivos y contenidos currículo - objetivos y contenidos centro

Objetivos y contenidos seminario/área - objetivos y contenidos profesor

Objetivos y contenidos alumnos - objetivos y contenidos terminales

Condiciones institucionales (horarios, aulas, grupos, tutorías, reglamento interno, etc.)

Situación de E/A ${ }^{8}$ en clase: gestión y participación en la E/A: el contrato pedagógico (gestión de los conflictos cognitivo, lingüístico y afectivo).

Análisis situación de enseñanza / aprendizaje de una secuencia didáctica específica

Objetivos y contenidos (Currículo y $\mathrm{PEC}^{9}$ ) en el curso/nivel precedente y en el siguiente

Objetivos y contenidos reales alcanzados $\left(\mathrm{PA}^{10}\right)$ en el curso/nivel precedente (media grupo clase en relación con el PEC)

Objetivos y contenidos previstos (Currículo y PEC) para el curso actual

Objetivos y contenidos previstos (PA) para el aula

Propuesta curricular de objetivos y contenidos

Contrato didáctico. Primeras concreciones de las hipótesis previstas

Criterios de secuenciación y de progresión helicoidal ${ }^{11}$ de unidades (base temática, por tareas, discursiva u otra)

Criterios de secuenciación de tareas y actividades en la unidad

Criterios de evaluación

Negociación (Correcciones a la propuesta curricular con las objeciones y sugerencias de los alumnos)

Proyecto curricular de aula (hipótesis de trabajo de aplicación directa)

Todos estos datos vertebran la planificación para alcanzar el objetivo fundamental: la competencia de comunicación/realización de lenguas, literaturas y culturas. Para ello hay que pasar por una larga etapa que es el proceso de construcción del nuevo sistema, este largo proceso va conformando un sistema intermedio que llamamos interlengua.

Estos análisis ponen de manifiesto que hay que saber aunar las distintas interacciones y relaciones para que el empirismo, con su buen sen- 
tido común, no se convierta en bricolaje desordenado, ni la teoría se reduzca a un esqueleto pegado a la piel de los documentos oficiales, ni la síntesis de las problemáticas generales un globalismo perdido en las nubes. Es necesario que el caos de la variedad tenga un sentido preciso para toda la comunidad educativa.

La progresión en la enseñanza/aprendizaje proporciona los criterios para avanzar desde la sensibilización hasta la conceptualización con los pasos necesarios de reflexión y de automatización para configurar la memoria a largo plazo.

Ejemplo de progresión de una secuencia anual

Objetivos «duros» del currículo, curso precedente:

1.-

2.-

3.-

$\mathrm{x} .-$

Objetivos «duros» del currículo, curso actual

1.-

2.-

$3 .-$

$\mathrm{x}$--

Progresión de los procedimientos y de las habilidades

Procedimientos

1. De recepción y percepción

2. De producción y creación

3. De reflexión, análisis y clasificación

4. De evaluación y de control

5. De afectividad y motivación

Habilidades

Habilidades primarias:

Comparar

Distinguir

Relacionar

Habilidades de orden medio:

Clasificar

Seriar

Razonar analógicamente

Inferir immediatamente

Habilidades de orden superior

Razonar silogisticamente 
Establecer criterios

Inferir mediatamente

Saberes

Saber (teórico, conceptual, técnico, científico, experto, etc.)

Saber hacer (procedimientos, habilidades y metahabilidades)

Saber aprender (aptitudes heurísticas)

Saber ser (perfiles físicos, psíquicos y cognitivos y actitudes)

Saber devenir (proyección en el futuro, curiosidad, ilusión ...)

Tipos de razonamiento

Reconocimiento y compresión

Clasificación

Relativización

Constitución de problemáticas

(Re)solución de problemas

\section{Organización del año escolar}

Objetivos «duros» del curso

1.-

2.-

3.-

x.-

Primera etapa: del . . . . . al . . . . .

Ciclos del objetivo duro Z.-

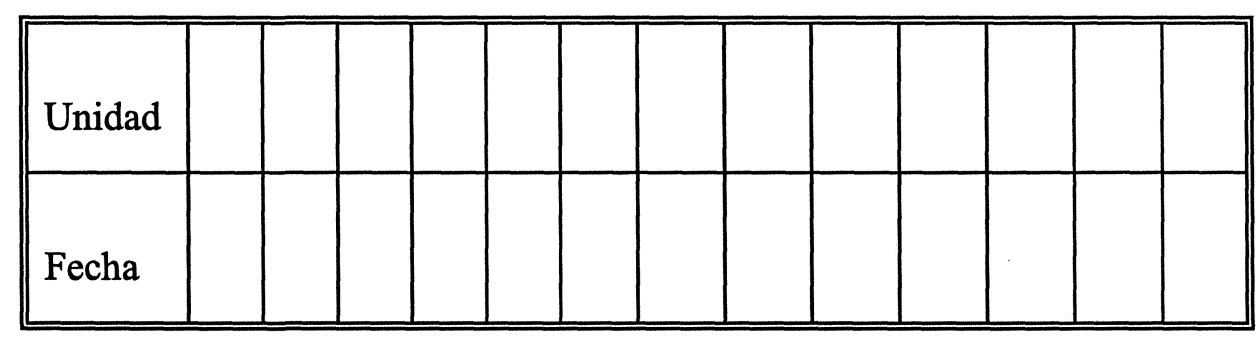

Ciclos del objetivo duro P.-

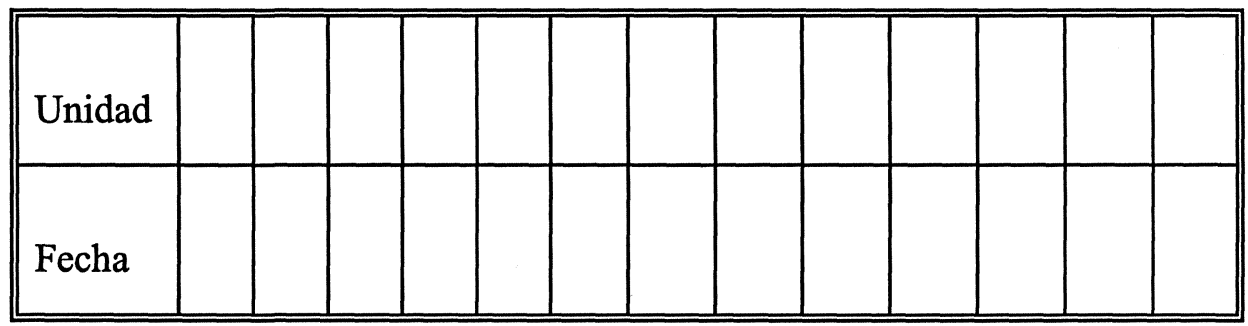


Ciclos del objetivo duro K.-

\begin{tabular}{||l|l|l|l|l|l|l|l|l|l|l|l|l|l||}
\hline Unidad & & & & & & & & & & & & & \\
\hline Fecha & & & & & & & & & & & & & \\
\hline
\end{tabular}

Segunda etapa: del . . . . a al . . . . .

Ciclos del objetivo duro A.-

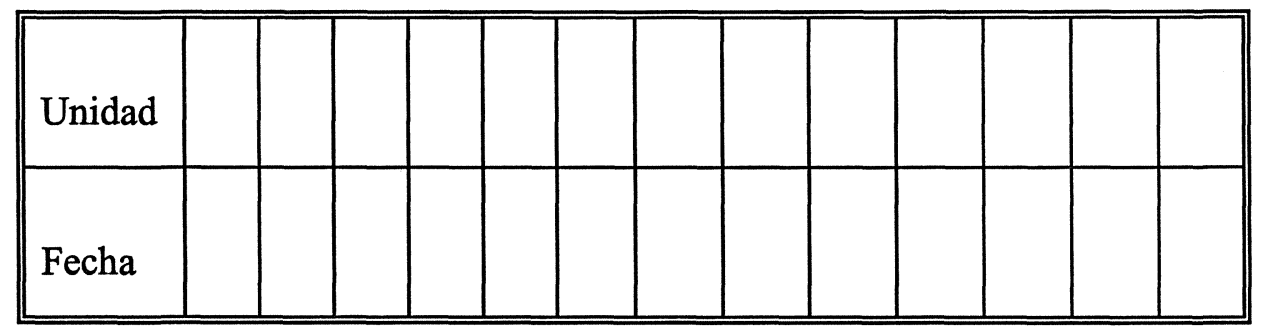

Ciclos del objetivo duro G.-

\begin{tabular}{||l|l|l|l|l|l|l|l|l|l|l|l|l|l||}
\hline Unidad & & & & & & & & & & & & & \\
\hline Fecha & & & & & & & & & & & & & \\
\hline
\end{tabular}

Ciclos del objetivo duro Ñ.-

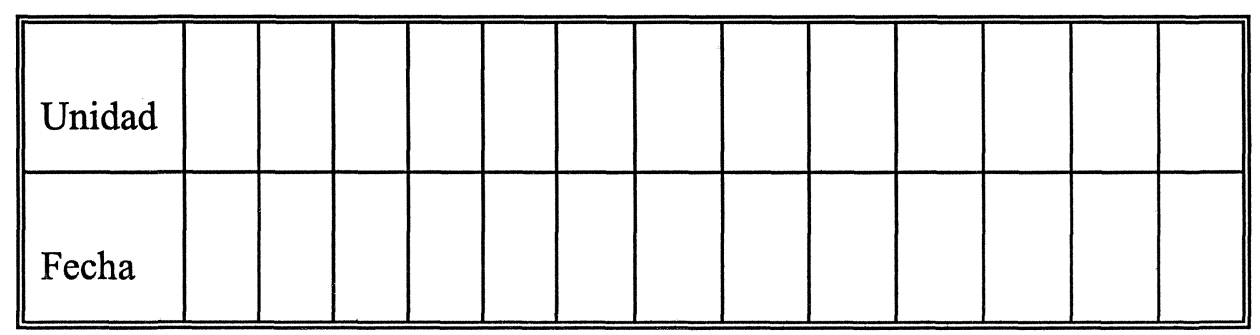




\section{Joaquín Díaz-Corralejo}

Secuencia de las unidades en sesiones (o lecciones)

Primer módulo o bloque de unidades

Unidad 1. Número previsible de sesiones en el tiempo y en un lugar

Objetivos operativos

Contenidos

Progresión de la competencia de comunicación y de cultura en la construcción del sentido

Progresión lingüística

Progresión léxica

Progresión pragmático-discursiva

Progresión socio-cultural

Progresión estrategias

Objetivos de evaluación

Criterios de evaluación y de remediación

Unidad 2. Número previsible de sesiones en el tiempo y en un lugar

Objetivos operativos

Contenidos

Progresión de la competencia de comunicación y de cultura en la construcción del sentido

Progresión lingüística

Progresión léxica

Progresión pragmático-discursiva

Progresión socio-cultural

Progresión estrategias

Objetivos de evaluación

Criterios de evaluación y de remediación

Segundo módulo

Se desarrolla igual

Tercer módulo

Etc.

\section{El desarrollo de la memoria}

En el desarrollo de la memoria se deben tener en cuenta los siguientes procesos (de la Garanderie 1982, pp. 79 y ss.) que se construyen a través de la lengua: 
La reflexión: Hay 4 tiempos en la reflexión: 1. percepción; 2. evocación; 3. rememorar las reglas, las nociones, los conocimientos; 4. aplicación de las reglas, las nociones, los conocimientos.

La memorización: Actividades: vaivén entre lo percibido y lo evocado; proyección hacia el futuro formando representaciones visuales o verbales y anticipando la utilización de éstas.

Memorizar: a) - estructurar, organizar la información

- crear asociaciones, relaciones entre les imágenes actuales y las representaciones a largo plazo

- reestructurar los conocimientos

- construir su saber, apropiárselo

- reutilizar en actividades de aprendizaje apropiadas a cada estudiante

Memoria a corto plazo: Capacidad de retener durante algunos segundos grupos de elementos («chunks»: trozos), normalmente no se retienen más que de tres a siete elementos. Existe el efecto de primacía, se retienen los primeros, y el efecto de inmediatez, se retienen los últimos, si no hay distracciones.

Hay varios módulos de la memoria a corto plazo (Baddeley y Hicht, 1994):

- el bucle y la autorepetición (como una cinta Moëbius)

- la pantalla visuo-espacial (las evocaciones aparecen bajo la forma de imágenes mentales visuales)

- el input fonético de los datos (almacenamiento fonético en elementos [sin bucle])

- la unidad de gestión central y la coordinación de módulos (supervisión de las operaciones de los módulos, ejecución simultánea de tareas independientes)

Memoria a largo plazo: Sistema complejo de memorias

- memoria procedimental: conocimiento de ciertas habilidades motrices y cognitivas (p.e.: preparación y ejecución de una tarea escolar)

- memoria proposicional o declarativa:

- la memoria episódica: recuerdos autobiográficos (afectiva)

- la memoria semántica: palabras, símbolos verbales, referentes, conceptos, reglas de operación de los símbolos y de sus relaciones; éstas pueden ser jerárquicas o en red, según la «distancia» semántica o mapa conceptual

- códigos de la memoria a largo plazo

- el código acústico

- el código simbólico, metafórico

- el código semántico 
Para la memorización, un aprendizaje intencionado, motivado, suscite una retención mejor que un aprendizaje incidental.

Para completar los criterios de dicha progresión se pueden utilizar las propuestas de las guías del profesor, el análisis de los manuales de clase, las propuestas institucionales: el currículo, el proyecto de centro y, fundamentalmente, la capacidad del propio docente para elaborar hipótesis a partir de la síntesis de todos los datos pasados por el filtro de la experiencia y del saber hacer profesional.

El diseño de las secuencias didácticas, para conseguir el objetivo básico de la competencia de comunicación y de cultura, debe establecer el porcentaje que tiene que tener específicamente en esa secuencia cada componente en relación con los objetivos didácticos, los contenidos y la evaluación.

Componentes de la competencia / actualización de comunicación $y$ de cultura

Lingüístico: gramatical, sintáctico y fonético/fonológico

Pragmático y discursivo:

no verbal: a) gestualidad; b) proxémica, mímica, gesticulación

verbal: a) situación de comunicación $\rightarrow$ actos de enunciación; b) tipos de textos $\leftrightarrow$ tipos de discurso $\leftrightarrow$ actos de habla; c) articulación, modalización y coherencia del texto

Referencial: a) nociones/temas; b) progresión semántica

Sociocultural: esfera personal, esfera social, esfera cultural (actualidad, arte, historia, etc.)

Estratégico: a) aprendizaje de metaestrategias: observación, comprensión, reflexión, estudio, etc.; b) estructuración de la reflexión: análisis, reflexión, argumentación, reformulación, síntesis, conceptualización, memorización; c) resolución de problemas: cognitivos, afectivos, sociales; d) rutinas, normas y dinámica del grupo clase; e) tratamiento de la información; f) gestión de los conocimientos y del proceso de enseñanza/aprendizaje: evaluación y autonomía

Por fin llegamos a la estructura básica que recoge todos los datos y hace una hipótesis de transposición didáctica al aula: la unidad didácti$c a$ (UD). Se puede definir como: Un conjunto coherente de actividades o tareas que, tras la transposición didáctica efectuada por el profesor, llevan al alumno del descubrimiento y comprensión de elementos y nociones nuevos, a su conceptualización, a su asimilación, a su fijación y a su transposición. Dicho conjunto se inscribe en una sucesión de fases o se- 
cuencias unidas por las hipótesis surgidas del análisis de la situación de enseñanza/aprendizaje con la finalidad de una adquisición óptima, siguiendo un proceso didáctico de progresión de contenidos, de lo simple a lo complejo y de lo concreto a lo abstracto.

Toda UD es el resultado de una opción metodológica. Todo profesor debe tener un conocimiento profundo de las distintas opciones para poder elegir con conocimiento de causa. En la «lección», el tiempo determinaba normalmente el contenido, en la UD son los contenidos los que determinan el tiempo, no tiene, por tanto, una duración preestablecida, ésta depende de los contenidos, de la metodología, de los niveles y del número de alumnos, etc.

Toda UD refleja las opciones metodológicas propuestas por el centro, el profesor, los alumnos, la administración y se caracteriza por un conjunto de procedimientos pedagógicos. Éstos varían según los niveles de aprendizaje y, en éstos, según las elecciones metodológicas, las condiciones de la situación de enseñanza/aprendizaje y las técnicas utilizadas. Tradicionalmente las UD se subdividían en dos fases: la «presentación» con varias etapas: presentación, repetición, memorización; y la «adquisición» con varias etapas también: explotación, fijación y transposición de las adquisiciones en la expresión personal y espontánea.

Actualmente, las fases de la UD deben tener en cuenta tareas y actividades, cambios conceptuales y resolución del/los conflicto/s cognitivo/s, de acuerdo con las hipótesis del aprendizaje significativo (Ausubel 68), de las actividades intelectuales y afectivas que se movilizan ante un nuevo conocimiento, según la taxonomía de D’Hainaut (Dalgalian et al. $1981 \mathrm{y}$ D'Hainaut 1985), que adapta al contexto escolar los planteamientos piagetianos y vigostkianos, así como la tarea final y la evaluación formativa de todo el proceso.

\section{Fases de la Unidad Didáctica}

\section{Motivación - Prerrequisitos}

En primer lugar, se trata de encontrar los elementos que pueden desencadenar y potenciar la motivación, (teniendo en cuenta que ésta se desarrolla en el ámbito afectivo de los alumnos, mediante la creación de imágenes mentales significativas o agradables, dichas imágenes mentales no siempre se traducirán verbalmente, pero están condicionadas por el lenguaje, hecho fundamental en el aprendizaje de otras lenguas y de la propia). Por lo tanto, para que las imágenes sean significativas hay 
que tener en cuenta lo socioafectivo (familiar, amistoso, cercano, instintivo). Se trata de mantener y fomentar la ilusión de aprender, de tener curiosidad; para ello se debería incorporar a las funciones comunicativas el componente imaginario personal. No hay que olvidar que habrá aprendizaje cuando haya un deslizamiento del hedonismo evolutivo (en principio, pasivo) a una evaluación crítica de las perspectivas de futuro (en principio, activa).

En segundo lugar, se deben analizar los prerrequisitos, es decir, aquellos conceptos, técnicas y estrategias, saberes y saber hacer, saber ser y saber devenir, que son necesarios para poder comprender e integrar los nuevos datos de la lengua extranjera en el sistema en construcción: la interlengua.

\section{Sensibilización - Recepción Fijación}

Las actividades de sensibilización, de conocimiento de lo nuevo, suelen ser actividades centradas en la comprensión oral y escrita, y en la expresión oral, en lengua extranjera (o en lengua materna, dependiendo del nivel de los alumnos). Estas actividades ponen en contacto al alumno con lo que quiere o debe aprender y se concretan en enumerar, identificar, reconocer, repetir, describir y memorizar.

\section{Conceptualización - Asimilación Adquisición}

Estas actividades tratan, cuando ya lo nuevo se ha hecho familiar para el alumno, de que éste lo incorpore a su propio sistema de lengua extranjera, mediante la interiorización, la memorización y la reconstrucción de sus propios conocimientos. A través de actividades y tareas analiza, clasifica y aprende a discriminar, rehusando y corrigiendo los enunciados que no correspondan al sentido en contexto. Sin conceptualización no hay verdadero aprendizaje, es decir, hay memorización a corto plazo y memorización por repetición.

Producción - Transferencia - Variación

Aunque las actividades de producción pueden darse en cualquiera de las fases anteriores, adecuadas al nivel de conocimientos y a la fase, la producción que no parafrasea, sino que elabora variando los conocimien- 
Reflexiones sobre la Didáctica...

tos adquiridos, en otras palabras, reutilizando los nuevos conocimientos y los antiguos combinándolos para responder a distintos contextos y en situaciones de comunicación diferentes, sólo puede realizarse, en principio, tras una buena conceptualización. Se concreta proponiendo al aprendiz lo que pueda ayudarle a avanzar haciéndole esforzarse a partir de lo conocido, mediante la producción creativa oral y escrita, personal o colectiva. No hay que olvidar el proporcionarle también la posibilidad y el desarrollo de la capacidad de analizarse y de autocorregirse.

La evaluación formativa sigue la progresión de las secuencias en sus distintas fases, observando y teniendo en cuenta los errores para analizar, diagnosticar y prescribir a los alumnos los elementos «obstáculo», sus propias limitaciones y las posibles correcciones o soluciones para conseguir las metas, los objetivos propuestos, las tareas finales acordados en el Contrato Pedagógico o Didáctico.

\section{Criterios de diseño de Unidades Didácticas}

1. Los criterios de desarrollo de la UD y su aplicación didáctica se plantean a tres niveles:

a) Situacional: responde a las preguntas básicas de toda situación de comunicación (cuándo, dónde, cómo, por qué, etc.), así como a la implicación e intencionalidad comunicativas de los interlocutores de los textos a utilizar en el aula en dicha UD. Desarrolla los roles lingüísticos, pragmáticos, referenciales, sociales, psíquicos y antropológicos de la competencia de comunicación y de cultura.

b) Secuencial: la progresión de la programación adopta una forma cíclica helicoidal, siguiendo como hilos conductores los elementos lingüísticos (grafémicos, fonológicos, fonéticos y morfo-sintácticos), pragmáticos (situación de enunciación, intenciones de comunicación, actos de habla, lo no verbal), referenciales (nociones y objetos del mundo creado), y textuales-discursivos (géneros de textos, tipos de discurso, coherencia, cohesión, modalización) teniendo en cuenta las secuencias establecidas por la administración (textos oficiales, proyecto educativo de centro) para la disciplina en ciclos y cursos, así como los análisis de la situación de enseñanza/aprendizaje.

c) Didáctico: parte del análisis de las necesidades, motivaciones y conocimientos de los alumnos para llegar a establecer el Contrato Didáctico que servirá, tras su negociación, de elemento dinamizador de la progresión en los sucesivos cambios (rupturas epistemológicas) que se darán a lo largo de la unidad, del curso. 
2. La progresión de la/s UD: toda UD es una unidad de aprendizaje en la que los criterios de progresión deben basarse en su característica de desarrollar las competencias múltiples citadas en 1.a). Hay que tener en cuenta, en dicha progresión, que el objetivo general global es la formación del alumno en las competencias de comunicación y de cultura en la lengua estudiada y en las estrategias y destrezas de tipo transversal interdisciplinar.

3. Debe haber una interrelación profunda de objetivos y contenidos (currículo, PEC, mínimos, conceptuales, procedimentales, actitudinales) entre las distintas unidades.

4. La selección de material, debe tener en cuenta lo dicho en 1,2 y 3 , para la elaboración de tareas y actividades (motivación, prioridades a desarrollar, consignas y rituales metalingüísticos, estrategias didácticas y dinámicas de grupo, tareas finales).

5. Las actividades y tareas serán organizadas, según los criterios de progresión citados anteriormente, en las fases del aprendizaje en una unidad didáctica: Motivación - Prerrequisitos; Sensibilización - Recepción - Fijación; Conceptualización - Asimilación - Adquisición; Producción - Transferencia - Variación; Evaluación formativa y formadora (durante todas las fases)

6. Imbricación de tareas y actividades entre si, con unidades anteriores y con unidades posteriores, según criterios de progresión.

7. Selección, según los criterios citados, de tareas y actividades de evaluación formativa y sumativa.

8. Previsión de actividades y tareas de refuerzo, según perfiles y estilos cognitivos de profesores y alumnos. Previsión de actividades laterales para situaciones inesperadas.

9. Evaluación de la propia unidad, criterios correctores de los aspectos no desarrollados y preparación de la transición a la unidad siguiente.

Las distintas culturas presentes en el aula deberán ser tenidas en cuenta en la elección de materiales de las lenguas y literaturas que proporcionarán unos textos y unos contextos ricos en experiencias significativas, funcionales y de contraste para todos los alumnos.

Este planteamiento didáctico puede ser un elemento de motivación de interés y, fundamentalmente, de fusión y de mestizaje cultural, que ayuden al/los profesor/es y al/los alumno/s a adquirir una competencia en la «cultura de la desaparición» (Gruzinski 2000, p. 330) para sobrevivir en una sociedad en la que el recurso a modelos sociales pasados o actuales en mutación es imposible y se trata de generar nuevas prácticas para evitar situaciones sin salida.

Estamentos, instituciones y familias de las diversas culturas presentes en el aula deberán proporcionar a los centros materiales e informa- 
ción para que el equipo educativo tenga los elementos necesarios para elaborar los criterios de culturas en contraste y en relación intercultural que den soluciones a los problemas cognitivos, afectivos y sociales. También se tienen que tener en cuenta las competencias transversales a todas las asignaturas:

Capacidad de escucha

Capacidad de atención

Capacidad de organización/reorganización de

actividades, ejercicios y tareas

conceptos, procedimientos y actitudes

tiempo y espacio

memorización

inducción, deducción e inferencia en el tratamiento de problemas sistematización de los elementos nuevos

tratamiento de la información

materiales

Su dominio, así como la integración de objetivos y contenidos de la lengua materna, de la lengua oficial y de la/las lengua/s extranjera/s, tendrá como objetivo la adquisición de una competencia plurilingüe y pluricultural en el campo de los conocimientos, de las representaciones, de los comportamientos y de los valores.

\section{5. ¿Crisis de la literatura?}

La enseñanza/aprendizaje de las lenguas, las literaturas y las culturas no debe olvidar unos hechos que forman parte de su historia educativa:

a) Crisis de un tipo de lectura: rechazo de un canon clásico y en relación con el pasado y, por tanto, de sus valores, en parte, por su dificultad para los lectores actuales. Transición de los valores culturales estatales o de comunidad hacia un canon internacional y multicultural.

b) Crisis de un cierto tipo de interpretación: rechazo de una idea del sentido de los textos y aparición de nuevos métodos de análisis difíciles de transponer al aula.

c) Crisis en los objetivos educativos: los enfoques que se centran en el alumno (tener en cuenta sus intereses, sus necesidades, sus capacidades, ...) atienden más a sus gustos que a los conocimientos, y hay una escasa visión histórica.

d) Crisis a nivel social e institucional: pérdida de estatus, de prestigio y de importancia para la formación o la selección en el mundo del trabajo. 


\section{Joaquín Díaz-Corralejo}

La consciencia de estos hechos ha llevado a las autoridades a aumentar las horas de lengua en el currículo para tratar de mejorar la situación. Esta decisión importante puede que dé resultado si parte de la constatación de que no hay método bueno para la educación de la inteligencia y que hay que preparar al estudiante en tres planos: culturas de la expresión, del aprendizaje y de la organización eficaz.

$\mathrm{Y}$, por supuesto, que saber lengua y saber literatura implica saber, en un caso, como usarla de forma espontánea, correcta e inteligente y, en el otro, el desarrollo de un canon personal, regional, nacional e internacional.

\section{La literatura}

Los objetivos generales de la enseñanza/aprendizaje de la literatura tratarían de conseguir una formación humanista, ideológica y que le permita dominar el texto y la lectura. En resumen, lo propuesto por Lázaro Carreter y por Núñez(Gabriel Núñez 1997, pp. 781-785).

Estos objetivos se desarrollarían a través del placer de unas lecturas plurales, multidimensionales, multidisciplinares, multiculturales, informativas, formativas y experienciales integradas en la planificación de la que hemos venido hablando y con el siguiente tratamiento en fases.

Fases de un enfoque multidimensional (Martos 1997, pp. 769-771; y Fernández 1997, pp. 743-746)

a) Fase afectiva: El texto en la experiencia personal emocional ${ }^{12}$. El texto en la percepción física, psíquica y cognitiva individual y grupal.

b) Fase social: el texto en su función sociocultural. El texto como comunicación.

c) Fase informativa: autor, argumento, tema, estructura.

d) Fase analítica: estudio de los diversos planos, fónico-fonológicoprosodemático, morfosintáctico, semántico.

e) Fase creativa: Intertextualidad, teatralidad, reescritura, producción lúdica, taller de escritura.

Parece claro por lo planteado hasta aquí que la polémica entre lingüística aplicada y didáctica es considerada como algo secundario ya que lo consideramos basado en cuestiones de tipo léxico, en inglés didactics no tiene el mismo sentido que en español, alemán o francés, y en as- 
pectos jerárquicos que hemos superado ya. Por eso no estamos de acuerdo con Álvarez Méndez (1998), ni con Widdowson (1998) a este respecto.

Nos parece más acertada la postura de A. Camps (1998) sobre su definición de Didáctica de la lengua y la literatura (Camps y Milian 1990, p. 34): «Espacio de acción sobre los procedimientos de enseñanza y de formación (...) una disciplina de intervención en el campo social». Aunque sigue siendo algo restrictiva, También Mendoza (1998, p. IV) habla de «intervención/aplicación», pero él mismo cita «la evolución lingüística/cognitiva del aprendiz» y de «las características procesuales de los contenidos objeto de aprendizaje» lo que implica una apertura a otras dimensiones del aprendizaje. El Consejo de Europa, en su Marco Europeo Común de Referencia para la Enseñanza, el Aprendizaje y la Evaluación de las lenguas, propone integrar la multidimensionalidad de la enseñanza/aprendizaje de las lenguas, así como tener en cuenta la afectividad y los aspectos mentales y volitivos de hablantes profesores y alumnos.

Dentro de esta multidimensionalidad habría que considerar la pluriculturalidad (Marco 1998, pp. 255-264; y Postigo 1988, pp. 265-274) con la que estamos de acuerdo, como hemos visto en las páginas precedentes, en que forma parte de la enseñanza/aprendizaje de las lenguas, las literaturas y las culturas.

J. M. Vez (1998, p. 78) propone «un concepto de didáctica de las lenguas que tenga en cuenta que los significados no están en el discurso» y que «los procesos de interacción en el aula (...) generan oportunidades para negociar esos significados». También Miquel Llobera (1998, pp. 369381) en un artículo demasiado corto y basándose en las propuestas constructivistas y en la pluriculturalidad plantea una hipótesis, a nuestro entender también restrictiva:

«El aprendizaje de las Lenguas Extranjeras en [...] una Europa plurilingüe [...] como objetivo la adquisición de la competencia comunicativa y cultural que facilite la interacción mediante el uso de lenguas diferentes de [la] lengua 1. [...]

El objetivo final de la enseñanza de todas las lenguas [...] presentes en el sistema educativo sería el de permitir el desarrollo de individuos con competencia plurilingüe y pluricultural [...] nos referimos a una dimensión humana y a una lingüística.»

Se puede adivinar una toma paulatina de posición, cada vez más clara, por un paradigma multidimensional de la didáctica de las lenguas, las literaturas y las culturas. Paradigma que ya apuntábamos más arriba y que repetimos ahora:

El proceso de enseñanza / aprendizaje del acceso al sentido a través de lenguas, literaturas y culturas 


\section{Continuará}

Sin más pretensión que apuntar algunas posibles soluciones a la transposición en el campo de la didáctica de la enseñanza/aprendizaje de las lenguas, las literaturas y las culturas, y de seguir el debate sobre la investigación e innovación en el campo de dicha disciplina, valgan estas líneas para dejar abierto el tema.

\section{Notas}

1 Vila, I. (2002): «Reseña de J. S. Bruner (2001): El proceso mental en el aprendizaje». Cuadernos de Pedagogía, n 310 (febrero).

2 Véase también, Hall, A. T. (1984): La danse de la vie. París: Seuil.

3 O mundos posibles, véase Eco, H. (1985): Lector in fabula. París: Grasset.

${ }^{4}$ No olvidemos que la literatura permite desarrollar la imaginación y captar el universo simbólico de una cultura.

5 En Estados Unidos y Francia.

${ }^{6}$ Las lenguas de prestigio social además de la materia suelen ser las lenguas cooficiales.

7 LO: Lengua Oficial; LM: Lengua Materna; LE: Lengua Extranjera.

8 E/A: Enseñanza/Aprendizaje.

9 PEC: Proyecto Educativo de Centro.

10 PA: Proyecto de Aula.

11 Se utiliza, cuando se habla de progresión, la metáfora de la espiral, pero ésta es una figura plana que sólo indica una progresión lineal y constante, para representar la progresión en el aprendizaje parece más correcto utilizar la imagen de la hélice que marca una progresión en el espacio y en el tiempo, que no tiene que ser lineal, que puede ser más rápida o más lenta, que puede incluso retroceder, y que puede variar de amplitud.

12 Recordemos un bello texto de López Parada: «un poema enseña la dimensión más privada de lo humano. Enseña al hombre el valor de su ser diferenciado y dibuja una huida hacia el rostro no común que es, en realidad, el deber de cualquier vida, la maduración hacia la propia conciencia y el papel propio".

\section{Bibliografía}

ÁlVAREZ MÉnDEZ, J. M. (1998): «Didáctica general y didáctica específica». En Conceptos clave en didáctica de la lengua y la literatura. Barcelona: Horsori, I.C.E. U.B., SEDLL.

Ausubel, D. P. (1968): Educational Psychology: A Cognitive View. New York: Holt. (Ed. Cast.: Psicología educativa. Un punto de vista cognoscitivo. México, Trillas).

GRABOT, E. (1994): Images mentales et stratégies d'apprentissage. París: ESF.

BRONCKART, J.-P. (1997): "Le texte comme lieu d'articulation de la didactique de la langue et didactique de la littérature.». En D.L.L. para una sociedad plurilingüe del siglo XXI, Actas IV Congreso SDLL, Barcelona, pp. 13-23. 


\section{Reflexiones sobre la Didáctica...}

BRUNER, J. (1990 y 1999): Actos de significado. Más allá de la revolución cognitiva. Madrid: Alianza.

CAMPS, A. (1998): «La especificidad del área de Didáctica de la lengua. Una visión sobre la delimitación de los contenidos de la enseñanza de la lengua y la literatura». En Conceptos clave en didáctica de la lengua y la literatura. Barcelona: Horsori, I.C.E. U.B., SEDLL.

Dalgalian, G., Lieutaud, S. Y Weiss, F. (1981): Pour un nouvel enseignement des langues, CLE int., Paris.

D’Hainaut, L. (1980): Des fins aux objectifs de l'éducation. Paris: Nathan; Bruxelles: Labor. (2e éd.)

D’HaInAUT, L. (1985): Objetivos didácticos y programación. Barcelona: Oikos-Tau. (1a. ed. Labor, Bruselas, 1995).

FERNÁNDEZ Contreras, R. (1997): “¿Hay que enseñar literatura?». En Didáctica de la lengua y la literatura para una sociedad plurilingüe del siglo XXI, Actas del IV Congreso SDLL, UB, Barcelona.

GALISSON, R. (1991): De la langue à la culture par les mots. París: CLE int.

De la Garanderie, A. (1982): Pédagogie des moyens d'apprendre. París: Le Centurion.

GARCí, E. (1994): Didáctica, nº 4, U.C.M.

GRAVEs, L. (07/11/1999): El País, p. 14.

JACQUES, F. (1987): «De la signifiance». Revue de Métaphysique et de morale, $\mathrm{n}^{\circ} 2$.

LÓPEZ PARADA, E. (09/02/2002): “Comentario a Tratado de las pasiones de Arturo Carrera". Babelia (El País), n 533, p. 10.

LÓPEZ VALERO, A. (1997): "Didáctica de la lengua y la literatura: estado de la cuestión». En Didáctica de la lengua y la literatura para una sociedad plurilingüe del siglo XXI, Actas del IV Congreso SDLL, UB, Barcelona.

MANACORDA DE ROSETTI, M. (1997): "El canon abierto elemento polisistemático». En Didáctica de la lengua y la literatura para una sociedad plurilingüe del siglo XXI, Actas del IV Congreso SDLL, UB, Barcelona.

MARCO, A. (1998): "Los aspectos de lo multicultural y su incidencia en el Área de Lengua y Literatura». En Conceptos clave en didáctica de la lengua y la literatura, Horsori, I.C.E. U.B., SEDLL, Barcelona.

MARTOS, E. (1997): «Situación de la didáctica de la literatura». En Didáctica de la lengua y la literatura para una sociedad plurilingüe del siglo XXI, Actas del IV Congreso SDLL, UB, Barcelona.

Mendoza Fillola, A. (coord.) (1998): Conceptos clave en didáctica de la lengua y la literatura. Barcelona: Horsori, I.C.E. U.B., SEDLL.

MORRIS (1971): Writing on the general theory of sign. La Haye: Mouton.

NÚÑEZ, G. (1997): «Hacia una moderna pedagogía de la literatura: la educación literaria ayer y hoy". En Didáctica de la lengua y la literatura para una sociedad plurilingüe del siglo XXI, Actas del IV Congreso SDLL, UB, Barcelona.

LLOBERA, M. (1998): «Ideaciones sobre la didáctica de lenguas extranjeras y segundas: consideraciones sobre un cambio de paradigma". En Conceptos clave en didáctica de la lengua y la literatura, Horsori, I.C.E. U.B., SEDLL, Barcelona.

Postigo, R. M. (1998): "Modelos de educación lingüística en contextos de lenguas en contacto». En Conceptos clave en didáctica de la lengua y la literatura, Horsori, I.C.E. U.B., SEDLL, Barcelona.

VEZ Jeremf́AS, J. M. (1988): «El bilingüismo. Aprendizaje de una lengua añadida». En Didáctica de la lengua y la literatura, García, J. y Medina, A. (dirs.). Madrid: Anaya. 
152

\section{Joaquín Díaz-Corralejo}

VEZ JEREMIAS, J. M. (1998): «Enseñanza y aprendizaje de las lenguas». En Conceptos clave en didáctica de la lengua y la literatura, Horsori, I.C.E. U.B., SEDLL, Barcelona.

VEZ Jeremías, J. M. (2001): Formación en didáctica de las lenguas extranjeras. Buenos Aires: Homo Sapiens.

YUS RAMOS (1996): «Temas transversales y educación global. Una nueva escuela para un humanismo mundialista». En Aula de innovación educativa, n. 51 . Barcelona: Graó.

WidDowson, H. G. (1998): "Aspectos de la enseñanza del lenguaje». En Conceptos clave en didáctica de la lengua y la literatura, Horsori, I.C.E. U.B., SEDLL, Barcelona. 